\title{
Research between Technology Standards and Patents in Mobile Publishing
}

\author{
Hejie Chen ${ }^{1,2}$ \\ ${ }^{1 .}$ School of Economic and management \\ Beijing Institute of Graphic Communication \\ 2. School of Economics and Management BUPT \\ Beijing University of Posts and Telecommunication \\ Beijing, China \\ chenhejie81@sina.com
}

\author{
Qiang Yan \\ School of Economics and Management BUPT \\ Beijing University of Posts and Telecommunication \\ Beijing, China \\ buptyan@gmail.com
}

\begin{abstract}
With the rapid development of wireless Internet and WIFI, mobile terminals have become an important media of content publishing. This paper presented our definition of mobile publishing. Then it described mobile publishing chain and participator's functions. The press provided the excellent contents in the whole industry chain. However, the press didn't control the industry chain and lost many profits. We considered patent and technology standards can increase the profit and function of the press. The press should actively take part in the patent race through cooperation with other enterprises. And the press gained the profit through patents. Since the patents are time limited and funds of the press are limited, the patent converted the technology standards to gain the long-term benefit. Government policies should encourage the press to participate in research of patent and technology standards.
\end{abstract}

Keywords-Patent; Technology Standards; Mobile publishing

\section{INTRODUCTION}

With the rapid development of mobile Internet and WIFI, mobile phone reading took on an explosive growth. According ten national reading survey, the rate of digital reading was $40.3 \%$ in 2012, which it increased $1.7 \%$ than in 2012 [1]. Many mobile devices are used, mobile digital reading increased.

The press, magazine and newspaper are traditional content suppler, but they didn't gain profit and control industry chain. Last many years, business, government and research found the way to improve content suppler profit. So, mobile publishing is proposed.

As a young industry, mobile publishing has no authoritative industry chain and profit model. According to our research, this paper presented a definition of mobile publishing. And mobile publishing industry chain is described. We considered patents and technology standards helped the press, magazine and newspaper to increase profits.

The paper is structured as follows. Section II provided mobile publishing concept and the mobile publishing industry chain. Section III introduced relationship between patents and technology standards of mobile publishing industry chain.

(The press, magazine and newspaper abbreviated the press as followings.)

\section{Mobile Publishing Definition}

So far, there is no authoritative definition of mobile publishing. Some research presented different concepts from self-domain. Mobile publishing is the mobile communication platform of press that can select book subject, edit content, publish, disseminate information, promote, market and aftersales service [2].The concept is defined from press domain. It emphasized on the mobile device completed the work process of press.

Mobile publishing is digital creating content process of books, newspapers, magazines and other content resource (for example, literary website).Digital resource management (DRM) is used to digital copyright protection. Digital content disseminate through the Internet, wireless networks, and storage devices. Users used the mobile devices to read or listen to the contents by software in anytime, anywhere [3].

This definition reflected the important parts of mobile publishing.

Firstly, providers of various content resources are traditional presses, magazines, newspapers. Other resource providers are literary website (for example, Shengda).

Secondly, a variety of specialized techniques applied to digital publishing. DRM is typically used to digital copyright protection.

Thirdly, different type's mobile devices finished reading or listening to the contents. Kindel, iPad and iPhone are typical mobile devices.

Fourthly, the mobile network operators are China Mobile, China Telecom, China Unicom.

Finally, users read and listen to the content by online or download the contents.

Due to the rapid development of Internet and mobile Internet, Web2.0 replaced Web1.0. The important and distinctive feature of Web2.0 is user participation that influenced the definition and development patterns of mobile publishing. According to Web2.0, we proposed a definition of mobile publishing as follow. Mobile publishing is that text, images, sounds and other content converted digital content through rigorous editing system processing, and digital content abided by the laws and regulations, the digital processing, the appropriate technology completed copyright protection, digital content disseminated through the Internet, mobile Internet, the user used mobile devices and the 
corresponding reading software to read the text, listen to audio, watch video files and other functions. Meanwhile, users can participate in interactive publications and complete compliance with the requirements of their own personal customized publications.

\section{Mobile Publishing Industry Chain AND THE PRESS FUNCTIONS}

\section{A. Mobile Publishing Industry Chain}

Our team considered that mobile publishing industry chain included equipment providers, network providers, service providers, content integrators, terminal providers, users.

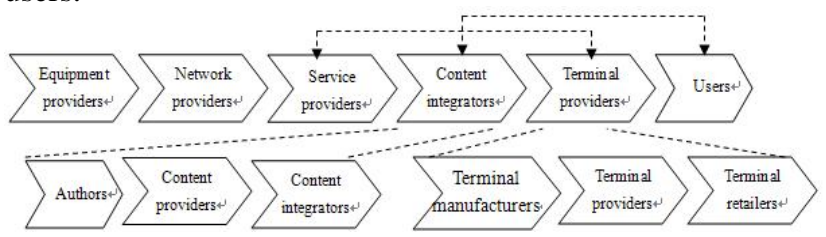

Figure 1. Mobile publishing industry chain

Services provided to users through menu and users pay according to information flow. Services providers didn't necessarily use the telecommunication system. In many countries such as Japan and China, network providers and services providers are the same entities.

The authors didn't refer to traditional authors who subscribed a contract with the publishing, but also referred the online writers, etc. The authors are the original content creators which provided the texts, images, cartoons and other contents for other people reading. Authors own the copyright of self-writing. They devised writings to the content providers and usually paid more attention to writing, but sometime they can play the role of content providers

Content providers usually didn't the authors. Service providers provided the available content to users through the menu. And users paid according to traffic. Service providers didn't own basic network, but they charge users according to the protocol and billing system. Network providers and Service providers are same in many countries such as Japan, China. The content providers not only aggregated a large number of contents from independent authors, but also ensured the legitimacy and true of contents. When the contents are spreading, the content providers ensured that the contents are not being illegally copied in the end.

Content providers provided the content to user through the website. Content providers usually didn't the authors. SP usually act as the content providers. Content integrators mainly collected different content from diverse authors or content providers to integrate into a specific website. Content integrators are known as portal site. In theory they focused on contents compounding and didn't created their own content. Telecommunication operators acted content integrators. In many countries, but they in china wanted to do more things. China Mobile set up an R \& D base to create contents in Zhejiang.

Terminal manufacturers are responsible for the terminal production. Terminals usually are mass production. Terminal manufactures independently researched and produced terminals. Sometimes they produced terminals according to standards provided by telecommunication operators.

Terminal providers play the bridge between terminal manufactures and retailers. Terminal retailers sold terminals to the consumers. They are traditional retail stores or any roles legally sold terminals. Mobile terminals included mobile phones, electronic reader. They can provide on-line or off-line reading functions through the telecommunication network or wireless internet network.

The customers not only read all kind of contents from traditional books, but also from new media which included digital library, digital books, the networks and mobile devices. On the other hand, the customers wanted the products of reasonable price and better service quality. It is noteworthy that customer participation is becoming increasingly important.

\section{B. The Press Functions in the Mobile Publishing}

Now the press has not done enough to the mobile publishing development. The press must actively research, develop and lay down the mobile publishing criteria. And the press protected the core resource of mobile publishing-content and copyright. The press must immediately seek a benefit distribution mode and control the copyright of the mobile publishing. At the same time, the press intensified cooperation with the developer of mobile publishing platform.

\section{The RELATIONSHIP BETWEEN PATENTS AND TEChNology Standards in Mobile Publishing}

\section{A. Technology Standards Improved the Function of the Press in Mobile Publishing}

The experience of selecting and displaying the content is accumulated by the press. Content influenced customers' satisfaction. So, the press should be an important part of mobile publishing. However, the press has little information knowledge. Then it lost the control power of mobile publishing. So, the press should develop the patents of contents in order to improve the function of industry chain.

Technology standards have international technology standards, national technology standards, industry technology standards. China has a strong protection of culture safety, so the press should firstly develop industry technology standards and finally convert international technology standards. State Administration of Press, Publication, Radio, Film and Television of The People's Republic of China helped the press developing the patents from policy and found. From the culture safety, government strengthened the presses' cooperation, developed some standards from the system and is forced the parties to obey the rules in the mobile publishing chain.

\section{B. The Press Strengthened to Cooperate with Other Enterprises through Technology Standards}

Features of technology standards are uniform, mandatory and restrained. That is that the participants received technology standards must comply with technology 
standards, product in accordance with its requirements. The press developed some patents and transformed them into standards. In the development process of the patents, the press found some cooperative enterprises. After a technology standard is authorized, the press not only gained the higher importance but also cooperated with more enterprises of mobile publishing chain.

\section{Technology Standards Help the Press to Maintain Superiority in Mobile Publishing}

A disadvantage of patents has the timeliness. When a patent closer to the date of termination, the patent has the lower market value. In information technology domain, technology refresh cycles are getting shorter. A patent usually is replaced by a comprehensive technical alternative before the period of validity. This is usually phenomenon that some enterprises devoted time and finance to develop a patent that gained no benefits out of date.

Since the press has less finance, it prevents the upper statement. It is the best way for the press that a patent converted into a technology standard. The technology standards have stability, because the members accepting the technology standards must use specified technology plan during the validity period. If the press converted a patent into a technology standard, the validity of the technology standards extended the period of validity of the patents. And the press can get more money to promote the technology standard that has forcible characteristics.

\section{International Technology Standards Help the Press to Identify International Position}

Region influenced application for patent, but it didn't restrict international technology standards. If it adopted for technology standard, especial international technology standard, a patent had the monopolistic market position without application for the patent in many countries. The press should actively participate in international technology standards. The press firstly understood the rule, participate in application in patent, ultimately converted into a international technology standards.

\section{ACKNOWLEDGMENT}

Institute Level Projects Funded by Beijing Institute of Graphic Communication E-b-2012-07

\section{REFERENCES}

[1] ten national reading survey, http://www.hnxwcb.com/web/zwdt/xydt/xyxw/04/23605.shtml

[2] Huang Chaoqin, Mobile publishing. Information on Publication, 2004(21), pp.21

[3] Zhu Yin, Mobile reading lights future publishing, China Publishing Journal, 2008(6), pp.59-60 